\title{
What is the Local Culture Teaching Strategy in BIPA Learning?
}

\author{
Muhamad Adji ${ }^{1}$, Sri Rijati ${ }^{2}$, and Yudi Permadi ${ }^{3}$ \\ ${ }^{123}$ University of Padjadjaran \\ m.adji@unpad.ac.id
}

\begin{abstract}
This paper is motivated by the importance of incorporating local cultural material into BIPA learning. Local culture is one form of Indonesian culture that is encountered by students in the local community. This paper tries to describe the importance of local cultural material in BIPA learning, local cultural material that BIPA learners need to learn, and the use of appropriate methods and media in cultural learning in the BIPA program. In this paper descriptive analytical methods are used. The results showed that learning local culture in BIPA learners could potentially eliminate cultural shock and increase better understanding of Indonesia. Appropriate local cultural material provided to BIPA learners is tangible cultural material that combines artifacts and cultural behavior of local communities, while intangible culture is an advanced material that is adjusted to the language competency of BIPA learners. The use of methods and media is contextual, in accordance with learning objectives, so it is very open to the merging of learning methods and media.
\end{abstract}

Keywords: BIPA, local culture, teaching strategy

\section{PENDAHULUAN}

Pembelajaran BIPA merupakan pembelajaran yang khas karena karakteristik dan norma pedagogik yang dimiliki oleh pembelajar BIPA berbeda dengan penutur bahasa Indonesia [1]. Faktor penyebab perbedaan tersebut selain struktur bahasa yang berbeda antara bahasa yang dipelajari dan bahasa pertama pembelajar, juga karena latar belakang budaya dan kebiasaan yang dimiliki oleh mereka [2]. Hal ini membuat pembelajaran BIPA memiliki tantangan tersendiri, baik bagi pengajar maupun bagi pembelajar.

Sebagai program pembelajaran bahasa, BIPA memiliki posisi yang strategis dalam diplomasi negara. Bahasa dan budaya memiliki kelebihan tersendiri dalam diplomasi negara karena memiliki sesuatu yang berbeda dengan model diplomasi yang menjadi arus utama (mainstream) [3]. BIPA tidak hanya menjadi ujung tombak bagi kebijakan Indonesia terkait dengan kebijakan internasionalisasi bahasa, tetapi juga menjadi pintu masuk bagi orang asing untuk mengenal dan memahami budaya Indonesia. Dengan demikian, program BIPA menjadi sarana yang efektif bagi Indonesia untuk memperkenalkan Indonesia kepada negara-negara di dunia.

Hasil analisis kebutuhan terhadap pembelajar BIPA tingkat madya yang dilakukan Arumdyahsari dan Susanto menunjukkan bahwa selain hal-hal yang berkaitan dengan desain dan isi materi, materi budaya juga diharapkan menjadi bagian materi BIPA [4]. Dari pernyataan di atas dapat disimpulkan bahwa selain desain materi ajar dan metode pembelajaran, aspek 
materi ajar BIPA yang berkaitan dengan budaya merupakan hal yang penting bagi pembelajar BIPA.

Artikel ini akan mengeksplorasi kebutuhan materi budaya lokal dalam pengajaran BIPA: 1) dasar argumentasi materi budaya lokal dibutuhkan dalam pengajaran BIPA, 2) Materi budaya lokal apa yang perlu disampaikan dalam pengajaran BIPA, dan 3) metode dan media pembelajaran yang tepat dalam penyampaian materi budaya lokal tersebut.

\section{METODE PENELITIAN}

Penelitian ini merupakan penelitian kualitatif. Sumber penelitian berupa sumber primer yang berasal dari observasi, kuesioner, dan hasil wawancara, sedangkan sumber sekunder berasal dari hasil penelusuran kepustakaan. Partisipan penelitian lapangan adalah pengajar dan pengelola BIPA di seluruh Indonesia, serta pembelajar BIPA di Pusat Bahasa, Fakultas Ilmu Budaya, Universitas Padjadjaran. Kedua sumber data ini dianalisis dan disajikan dalam tulisan dengan menggunakan metode deskriptif analitis.

\section{HASIL DAN PEMBAHASAN}

Dalam membangun hubungan baik antarbangsa, program BIPA merupakan salah satu langkah yang tepat. Hal ini pula yang menjadi alasan Badan Pengembangan Bahasa dan Perbukuan menjadikan pengajaran BIPA sebagai salah satu ujung tombak dalam program internasionalisasi bahasa Indonesia. Internasionalisasi bahasa Indonesia tidak hanya bertujuan mengusung kepentingan agar bahasa Indonesia dikenal dan digunakan di banyak negara, tetapi juga untuk menjadikan Indonesia dikenal dan dihargai oleh negara-negara lain. Oleh karena itu, dalam kaitannya dengan hal tersebut, materi budaya merupakan hal yang penting dalam pembelajaran BIPA.

Pengajaran BIPA tidak hanya bertujuan menjadikan pembelajar BIPA mahir berbahasa Indonesia dengan baik, tetapi juga membuat mereka memahami konteks sosiokultural orangorang Indonesia [5]. Kepentingan orang asing belajar BIPA bukan sekadar mahir dalam berbahasa Indonesia, tetapi dapat memiliki pemahaman yang utuh dan lebih lengkap sehingga mereka dapat berkomunikasi dalam konteks kultur Indonesia [6]. Oleh karena itu, keberhasilan pengajaran BIPA tidak akan optimal apabila pengajaran itu tidak melibatkan aspek-aspek sosial budaya yang berlaku dalam masyarakat bahasa tersebut [5] karena bahasa sangat dipengaruhi oleh kebudayaan [7]. Bahasa merupakan aspek budaya yang juga menjadi alat untuk mengekspresikan nilai-nilai budaya dari masyarakat [8]. Segala hal yang ada dalam kebudayaan akan tecermin di dalam bahasa karena bahasa menyimpan perbendaharaan budaya yang terefleksi dalam benda-benda, perilaku, serta kegiatan yang dilakukan oleh masyarakatnya.

Sebagai pembelajar BIPA yang tinggal di suatu tempat di Indonesia, orang asing perlu mengenali budaya lokal tempat ia hidup dan berinteraksi dengan masyarakat setempat. budaya setempat memiliki kekhasan tersendiri yang membedakannya dengan budaya di daerah yang lain, yang dalam konteks tertentu dapat memunculkan kesalahpahaman pada orang asing mengenai Indonesia. Dalam satu contoh kasus, orang asing pembelajar BIPA yang datang ke Maluku pernah mengalami keterkejutan ketika mengetahui bahwa makanan pokok daerah tersebut adalah papeda yang terbuat dari sagu karena dalam pemahamannya selama ini, makanan pokok orang Indonesia adalah nasi.

Kesalahpahaman seperti ini muncul karena budaya Indonesia yang dikenal oleh dunia luar adalah budaya Indonesia yang menjadi arus utama (mainstream). Oleh karena itu, untuk menunjukkan kepada orang asing tentang begitu beragamnya budaya Indonesia, perlu 
diperkenalkan budaya lokal. Budaya lokal tidak hanya membuat orang asing tersebut memiliki daya tahan hidup (survival) di lingkungan sosial budayanya yang baru, tetapi juga dapat membawanya memiliki pemahaman yang lebih baik terhadap budaya masyarakat setempat secara khusus dan Indonesia secara umum. Oleh karena itu, materi budaya lokal menjadi suatu kebutuhan dalam pengajaran BIPA agar memudahkan jalan bagi pembelajar BIPA untuk mengenali lebih dalam budaya Indonesia. Pemahaman aspek budaya juga dapat menumbuhkan tata krama dalam diri pembelajar BIPA ketika berkomunikasi dengan masyarakat penutur jati [9].

Masalahnya adalah tidak semua materi ajar BIPA yang dicetak memasukkan materi budaya Indonesia, terlebih lagi budaya lokal. Dari penelitian yang dilakukan Mustakim [5], dari 43 buku yang diteliti, terdapat 24 buku (56\%) buku yang menyajikan materi sosial budaya Indonesia. Hal itu berarti ada 19 buku (44\%) yang belum menyajikan aspek sosial budaya Indonesia secara optimal. Dari 19 judul itu sebanyak 11 buku tidak menyajikan sama sekali aspek sosial budaya, sedangkan yang lain ada menyinggungnya, tetapi porsinya sangat sedikit [5]. Jika dilihat secara angka kuantitatif, hal ini menunjukkan bahwa materi budaya belum menjadi prioritas utama dalam pengajaran BIPA. Namun, jika dilihat dari prosesnya, ada perkembangan yang lebih baik yang menunjukkan kesadaran dari pengelola/ pengajar BIPA untuk memasukkan unsur budaya ke dalam pengajaran BIPA. Kekurangan materi ajar yang minim unsur budaya dapat disiasati oleh pengajar BIPA dengan merancang sendiri materi budaya yang dipadukan dengan metode dan media pembelajaran yang tepat. Oleh karena, itu pemahaman yang baik pengajar BIPA terhadap tujuam pembelajaran BIPA menjadi hal yang penting menjembatani kekurangan yang ada pada bahan ajar tersebut [3].

Yang perlu dipikirkan pada tahap selanjutnya adalah budaya lokal yang bagaimana yang menjadi prioritas materi ajar BIPA. Beberapa pandangan merujuk pada konsep budaya berdasarkan pandangan C. Kuckhohn tentang tujuh unsur budaya [10]. Ruskhan [5] mengelaborasi tujuh unsur budaya tersebut ke dalam berbagai contoh sehingga mudah untuk diturunkan dalam materi ajar. Misalnya, sistem peralatan dan perlengkapan hidup dapat diuraikan ke beberapa materi yakni alat produktif, alat distribusi dan transportasi, wadah dan tempat untuk menaruh, makanan dan minuman, pakaian, perumahan, dan lain-lain. Sementara itu, Mustakim [5] mengelompokkan materi yang perlu disajikan dalam buku ajar BIPA di antaranya benda-benda budaya, gerak-gerik anggota badan, jarak fisik ketika berkomunikasi, kontak pandang mata dalam berkomunikasi, penyentuhan, adat-istiadat yang berlaku dalam masyarakat.

Menurut penulis, topik-topik materi budaya yang disampaikan oleh Ruskhan dan Mustakim cukup berterima meskipun masih dapat didiskusikan kembali. Penulis berpijak pada ketegori wujud budaya yang dirumuskan oleh J.J. Honigmann yang membagi wujud budaya ke dalam tiga kategori yakni 1) idea/ gagasan, 2) activities/ kegiatan, dan 3) artifact (artefak) [10]. Artefak dan aktivitas adalah wujud budaya yang terlihat (tangible), sedangkan gagasan atau nilai-nilai adalah wujud budaya yang tidak terlihat (intangible). Untuk mengetahui dan memahami sistem budaya suatu kelompok masyarakat, orang asing perlu mengetahui unsur-unsur budaya yang terlihat (tangible). Dalam kaitannya dengan pembelajaran BIPA, yang perlu diketahui terlebih dahulu pada budaya lokal adalah budaya tangible, yang meliputi artefak dan aktivitas. Hal ini sejalan dengan paradigma cultural studies bahwa budaya merupakan "teks dan praktik hidup sehari-hari” [11].

Unsur budaya tangible yang perlu dipelajari adalah unsur budaya yang lekat dengan kehidupan sehari-hari pembelajar BIPA di antaranya: 1) jenis-jenis makanan, minuman, dan pakaian, 2) jenis-jenis kesenian 3) adab dan kebiasaan sehari-hari, dan 4) upacara dan tradisi. Tentu yang perlu dipelajari oleh pembelajar BIPA adalah apa yang tampak secara kasat mata 
(budaya tangible) oleh mereka. Budaya tangible adalah pintu masuk bagi pembelajar BIPA untuk mengetahui dan memahami nilai-nilai budaya kelompok masyarakat di Indonesia.

Dalam interaksi antarbangsa, perilaku keseharian suatu kelompok masyarakat tentu mengundang pertanyaan dan rasa penasaran bagi kelompok masyarakat lain. Misalnya, perilaku keseharian orang Sunda yang selalu membubuhkan cabai pada makanan mereka. Dalam beberapa kasus pada program BIPA Unpad, rasa penasaran pembelajar BIPA terhadap makanan pedas tersebut berujung pada sakit perut yang berkepanjangan. Contoh lainnya, kebiasaan orang Sunda yang selalu tersenyum dan menyapa di jalan dengan pertanyaan-pertanyaan berulang dan retorik juga merupakan perilaku yang asing bagi orang asing pembelajar BIPA. Bagi orang Eropa/ Amerika, pertanyaan-pertanyaan seperti "mau ke mana? Sudah punya pacar/ keluarga?" adalah pertanyaan yang tidak biasa ditanyakan kepada orang yang baru dikenal. Materi budaya yang berkaitan dengan kebiasaan masyarakat setempat jika tidak diperkenalkan dalam pengajaran BIPA, dapat berpotensi membuat orang asing mengalami gegar budaya (cultural shock). Di sisi lain, materi budaya yang ditindaklanjuti dengan pengalaman budaya akan membuat pembelajar BIPA semakin terampil menggunakan bahasa Indonesia [12]. Oleh karena itu, penting kiranya jika budaya lokal menjadi bagian dari materi ajar BIPA agar pembelajar BIPA dapat bertahan hidup dan mudah beradaptasi dengan masyarakat setempat di Indonesia. Hal ini sejalan dengan penelitian Muliastuti [13] yang menunjukkan bahwa pembelajar BIPA memerlukan materi budaya yang berkaitan dengan nilai-nilai sopan santun pada masyarakat Indonesia, aktivitas atau kebiasaan yag dilakukan, serta artefak budaya seperti candi, dan rumah adat. Penelitian Prasetiyo [14] terhadap budaya Jawa sebagai bahan ajar BIPA juga menunjukkan bahwa tujuh unsur budaya seperti yang dikemukakan Koentjaraningat dapat dijadikan muatan materi dalam pengajaran BIPA. Dalam satu buku ajar BIPA yang dikembangkan di Jawa Timur, aspek makanan dan budaya khas Jawa Timur menjadi hal utama yang dimunculkan dalam buku ajar tersebut [15].

Terkait dengan pembelajaran budaya bagi pembelajar BIPA, penggunaan metode pembelajaran sangat bergantung pada tujuan pembelajaran. Hal ini sejalan dengan pandangan Percival \& Ellington bahwa metode berkenaan dengan cara menyampaikan materi kepada pembelajar agar tujuan pembelajaran tercapai [16]. Pengajar BIPA dapat menggunakan salah satu atau menggabungkan metode pembelajaran dalam praktik pembelajaran. Pembelajaran tidak hanya terpaku di dalam kelas, tetapi juga dapat dipadukan dengan pembelajaran di luar kelas yang melibatkan interaksi antara pembelajar BIPA dan masyarakat lokal.

Hal ini sejalan dengan hasil penelitian Sudaryanto yang menunjukkan bahwa pembelajaran BIPA tentang budaya dapat berlangsung luar kelas maupun dalam kelas [17]. Situasi kebahasaan yang terjadi di dalam kelas dan luar kelas tentu sangat berbeda. Pembelajar BIPA akan menemukan atmosfer pembelajaran yang berbeda dalam pembelajaran luar kelas yang membuatnya semakin tertuntut untuk terampil menemukan kosakata atau pilihan kata dan mengonstruksinya ke dalam kalimat bahasa Indonesia [18].

Selain metode pembelajaran, penggunaan media pembelajaran juga dapat dipadukan antara media luring (offline) dan daring (online). Pemaduan berbagai metode dan media pembelajaran budaya lokal dimaksudkan agar tujuan pembelajaran dapat tercapai. Hasil kuesioner yang dibagikan kepada 60 pengajar dan pengelola BIPA di Indonesia dan luar negeri menunjukkan bahwa $87 \%$ telah menggunakan media daring, sedangkan $13 \%$ masih menggunakan media luring. Persentase di atas menunjukkan bahwa semakin banyak pengajar/ pengelola BIPA yang memanfaatkan media daring dalam pembelajaran. Semakin intensnya penggunaan media daring disebabkan media ini lebih mudah diperoleh. Dengan akses internet yang baik, pengajar dapat mengakses materi budaya yang dibutuhkan untuk digunakan dalam pembelajaran. Sementara itu, 75\% pembelajar BIPA Unpad menyetujui penggunaan media pembelajaran yang bervariasi, 
Gambar 1. berikut menunjukkan beberapa metode dan media pembelajaran yang dapat digunakan dalam materi pembelajaran budaya lokal.

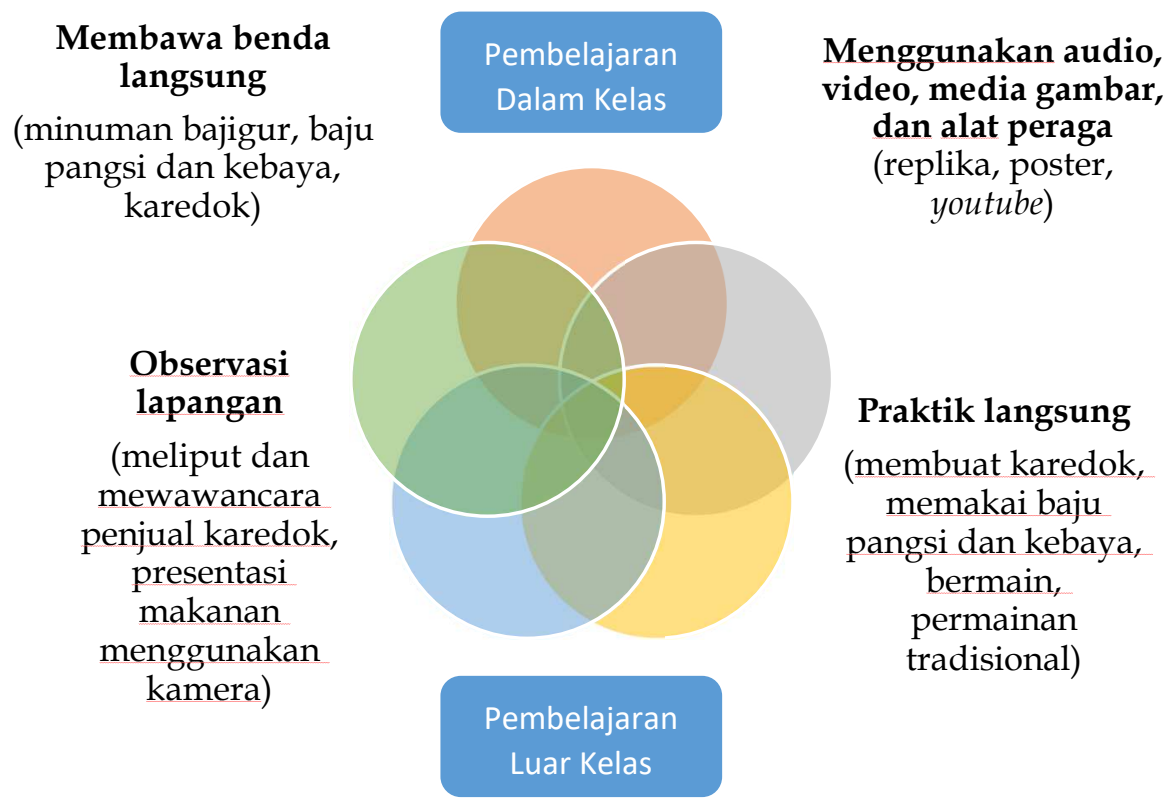

Gambar 1. Metode dan Media Pembelajaran berbasis Budaya Lokal

Gambar 1. menunjukkan potensi kemungkinan yang dapat dilakukan dalam pembelajaran budaya. Dari diagram di atas dapat disimpulkan bahwa pembelajaran budaya dapat menggabungkan berbagai metode dan media pembelajaran bergantung pada tujuan pembelajaran. Ketersediaan dan kemudahan teknologi informasi melalui internet juga memudahkan pengajar untuk menggunakan media daring sebagai pelengkap atau pengganti media luring.

\section{PENUTUP}

Pengenalan budaya lokal menjadi kebutuhan bagi pembelajar BIPA yang tinggal di suatu tempat di Indonesia. Selain untuk meminimalkan potensi gegar budaya (cultural shock) pada orang asing pembelajar BIPA, pemberian materi budaya lokal dalam pengajaran BIPA dapat mendekatkan pembelajar BIPA dengan masyarakat sehingga tercipta pemahaman yang lebih baik atas budaya yang ada di Indonesia. Dalam konteks ini, peran diplomasi budaya yang diemban oleh pengajaran BIPA secara tidak langsung telah dilakukan.

Budaya tangible menjadi materi budaya yang tepat untuk memudahkan pembelajar BIPA memahami budaya lokal dan membuatnya mudah beradaptasi dengan masyarakat setempat. Budaya intangible dapat menjadi materi lanjutan dalam pembelajaran BIPA, disesuaikan dengan kompetensi berbahasa pembelajar BIPA. Agar proses pembelajaran berjalan efektif dan tujuan pembelajaran budaya lokal dapat tercapai dengan baik, perlu dipadukan berbagai metode dan media pembelajaran dalam penyampaian materi budaya, baik menggunakan pembelajaran dalam kelas atau pembelajaran luar kelas, maupun menggunakan menggunakan media daring atau media luring. 


\section{REFERENCES}

[1] A. M. N. Setiawan, A. Andayani, and K. Saddhono, "The Use of Writing Learning Media for Bipa Students to Understand Local Culture," Komposisi J. Pendidik. Bahasa, Sastra, dan Seni, vol. 18, no. 1, p. 66, 2017.

[2] I. Suyitno, "Aspek Budaya dalam Pembelajaran Bahasa Indonesia bagi Penutur Asing (BIPA)," in Bahasa dan Sastra Indonesia dalam Konteks Global, 1997, pp. 55-70.

[3] R. Agustina; Andayani; N.E. Wardani, "Implementasi Pembelajaran Bahasa Indonesia bagi Penutur Asing di UPT P2B Universitas Sebelas Maret Surakarta," J. Pendidik. Bhs. dan Sastra, vol. 1, no. 2, pp. 140-154, 2013.

[4] S. Arumdyahsari, W. Hs, and G. Susanto, "Pengembangan Bahan Ajar Bahasa Indonesia bagi Penutur Asing (BIPA) Tingkat Madya," J. Pendidik. Teor. Penelitian, dan Pengemb., vol. 1, no. 5, pp. 828-834, 2016.

[5] A. G. Ruskhan, "Pemanfaatan Keberagaman Budaya Indonesia dalam Pengajaran Bahasa Indonesia bagi Penutur Asing (BIPA)," Sawerigading, vol. 16, no. 1, pp. 8188, 2010.

[6] F. Junaidi, R. Andhira, and E. Mustopa, "Implementasi Pembelajaran BIPA Berbasis Budaya sebagai Strategi Menghadapi MEA," in The 1st Education and Language International Conference Proceedings Center for International Language Development of Unissula, 2017, pp. 317-324.

[7] L.S. Aslinda, Pengantar Sosiolinguistik. Bandung: Refika Aditama, 2010.

[8] K. Saddhono, "Integrating Culture in Indonesian Language Learning for Foreign Speakers at Indonesian Universities," J. Lang. Lit., vol. 6, no. 2, 2015.

[9] D. F. Rohimah, "Internasionalisasi Bahasa Indonesia dan Internasionalisasi Budaya Indonesia melalui Bahasa Indonesia bagi Penutur Asing (BIPA)," An-Nas J. Hum., vol. 2, no. 2, pp. 199-211, 2018

[10] Koentjaringrat, Antropologi 1. Jakarta: Gramedia, 2005.

[11] J. Storey, Cultural Studies dan Budaya Pop. Yogyakarta: Jalasutra, 2007.

[12] J. Susilo, "Pengembangan Kurikulum Bahasa Indonesia bagi Penutur Asing," Deiksis J. Pendidik. Bhs. dan Sastra Indones., vol. 3, no. 1, pp. 44-53, 2016.

[13] L. Muliastuti, "Penyebaran Bahasa dan Sastra Indonesia melalui Pengajaran BIPA dan Ekspedisi Budaya,” Kongres Bahasa Indonesa XI, Jakarta, 2018.

[14] A.E. Prasetiyo, "Pengembangan Bahan Ajar Bipa Bermuatan Budaya Jawa Bagi Penutur Asing Tingkat Pemula," Lingua, vol. 11, no. 1, 2015.

[15] P. Suher, S; Hermoyo, "Pengembangan Materi Ajar Bipa Melalui Budaya Lokal Jawa Timur," Elem. Sch. Educ. Journal), vol. 1, no. 1, pp. 48-56, 2017.

[16] M. Rianto, "Pendekatan, Metode, dan Strategi Pembelajaran." Departemen Pendidikan Nasional Direktorat Jenderal Peningkatan Mutu Pendidik dan tenaga Kependidikan, 2006.

[17] Sudaryanto; Hermanto; L. Mahduroh; M.A. Hermawan; A.Z. Xirana, "Literasi Mahasiswa Bipa Program Darmasiswa Universitas Ahmad Dahlan Bermuatan Bahasa Dan Budaya Indonesia," J. Ilmu Pendidik. Bhs. dan Sastra Indones., vol. 3, pp. 57-66, 2018.

[18] K. Saddhono, "Integrating culture in Indonesian language learning for foreign speakers at Indonesian universities,” J. Lang. Lit., vol. 6, no. 2, 2015. 